\title{
PW03-010 - MHC complexity in Behçet's disease
}

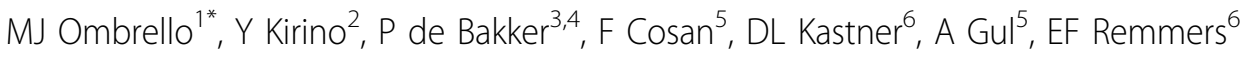 \\ From 7th Congress of International Society of Systemic Auto-Inflammatory Diseases (ISSAID) \\ Lausanne, Switerland. 22-26 May 2013
}

\section{Introduction}

Family studies support a genetic contribution to Behçet's disease (BD), with a sibling recurrence-risk ratio of 1152. The class I MHC molecule, $H L A-B * 51(B * 51)$, is the strongest known genetic risk factor for $\mathrm{BD}$, however the gene immediately centromeric to $H L A-B, M I C A$, has also been implicated in $\mathrm{BD}$. Because of strong linkage disequilibrium (LD) between $H L A-B$ and MICA, their respective contributions to BD susceptibility have been debated. A recent report has proposed that $B * 51$ is not a BD susceptibility allele, and several studies have identified $B * 51$ independent association signals within the MHC.

\section{Objectives}

To clarify the relationship between $B * 51$ and $\mathrm{BD}$, and to test for $B * 51$-independent genetic variation within the MHC that influences BD susceptibility.

\section{Methods}

Using Illumina Human 370CNV SNP genotypes in a Turkish collection of 1244 BD patients and 1303 geographically-matched healthy subjects, we examined SNP haplotypes and LD patterns across the $H L A-B / M I C A$ region with Haploview. We performed SNP imputation of the MHC using IMPUTE2 and the 1000 Genomes Phase 1 dataset. We inferred classical HLA types and their amino acids using SNP2HLA. Association testing and regression analyses were performed using SNPTEST and SNP \& Variation Suite 7.

\section{Results}

We identified a $B * 51(+) H L A-B / M I C A$ haplotype that was strongly associated with $\mathrm{BD}(\mathrm{p}=1.22 \mathrm{E}-46$, OR 2.8$)$. A $B * 51(-)$ version of the same haplotype occurred at equal frequencies in cases and controls, demonstrating that $B * 51$ is essential to the risk haplotype. Further, we found that rs2848713, a variant on the MICA end of the

\footnotetext{
${ }^{1}$ Translational Genetics and Genomics Unit, NIAMS, Bethesda, USA Full list of author information is available at the end of the article
}

haplotype, conferred additional risk of BD in $B * 51(+)$ individuals. Through imputation, we generated a set of 32,689 imputed SNPs. The 2 most strongly associated SNPs were $4.8 \mathrm{~Kb}$ centromeric of $H L A-B\left(\mathrm{p}_{\min }=1.4 \mathrm{E}-50\right)$, but no SNP was more strongly associated with BD than was $B * 51$ itself $(\mathrm{p}=1.3 \mathrm{E}-55)$. Conditioning on $B * 51$ revealed an association near $H L A-A$ ( $\left.\mathrm{p}_{\min }=5.4 \mathrm{E}-9\right)$, and upon adding a representative $H L A-A$ SNP to the regression model, we detected residual association centromeric of HLA-B ( $\mathrm{p}=1.5 \mathrm{E}-5)$. Analysis of imputed HLA types supported these findings. In addition to the association of $\mathrm{BD}$ with $B * 51 \quad(\mathrm{p}=2.2 \mathrm{E}-55)$, sequential regression of imputed HLA types identified associations of $H L A-A * 03$ $(\mathrm{p}=1 \mathrm{E}-8), H L A-C * 0701(\mathrm{p}=9.5 \mathrm{E}-4)$, and $H L A-B * 15$ $(\mathrm{p}=1.2 \mathrm{E}-4)$ with BD. Stepwise forward regression of imputed $H L A-B$ amino acids identified $6 H L A-B$ residues that together fully accounted for the regional association at $H L A-B$.

\section{Conclusion}

This study affirms $B^{*} 51$ as the strongest risk factor of $\mathrm{BD}$. We have provided strong evidence opposing a $B * 51$-independent role for $M I C A$ variants in BD susceptibility. We have identified significant effects of $H L A-A^{*} 03$ and $H L A-C^{*} 0701$, which protect against $\mathrm{BD}$, and $H L A-B^{*} 15$, which confers risk of $\mathrm{BD}$. We have identified a group of $H L A-B$ amino acids, most of which reside in the antigen binding groove, that together account for the entire association signal at the $H L A-B$ locus.

\section{Disclosure of interest}

None declared.

\section{Authors' details}

${ }^{1}$ Translational Genetics and Genomics Unit, NIAMS, Bethesda, USA.

${ }^{2}$ Department of Internal Medicine and Clinical Immunology, Yokohama City University, Yokohama City, Japan. ${ }^{3}$ Division of Genetics, Brigham and

Women's Hospital and Harvard Medical School, Boston, USA. ${ }^{4}$ Departments of Medical Genetics and of Epidemiology, University Medical Center Utrecht, 
Published: 8 November 2013

doi:10.1186/1546-0096-11-S1-A236

Cite this article as: Ombrello et al:: PW03-010 - MHC complexity in Behçet's disease. Pediatric Rheumatology 2013 11(Suppl 1):A236.

Submit your next manuscript to BioMed Central and take full advantage of:

- Convenient online submission

- Thorough peer review

- No space constraints or color figure charges

- Immediate publication on acceptance

- Inclusion in PubMed, CAS, Scopus and Google Scholar

- Research which is freely available for redistribution

Submit your manuscript at www.biomedcentral.com/submit
() Biomed Central 